\title{
THE DISTRIBUTION OF IOM TEMPERATURES ON THE ROSS ICE SHELF
}

\author{
By R. H. Thomas \\ (Ross Ice Shelf Project, University of Nebraska-Lincoln, I35 Bancroft Hall, Lincoln, \\ Nebraska 685o8, U.S.A.)
}

\begin{abstract}
Ten-meter temperatures on the Ross Ice Shelf increased by I deg between 1958 and 1974 . Surface temperatures at the "Byrd" and McMurdo stations have also risen during this period and the observed change is consistent with the $10 \mathrm{~m}$ temperature increase. This rising trend in temperature appears to have an anti-phase relationship with northern hemisphere cooling.

RÉsumé. La distribution des températures sur les dix premiers mètres du Ross Ice Shelf. Les températures sur les dix premiers mètres du Ross Ice Shelf se sont accrues de I deg entre $195^{8}$ et 1974. Les températures de surface aux stations "Byrd" et McMurdo ont aussi augmenté pendant cette période, et les changements observés sont cohérents avec l'accroissement de température sur dix mètres. Cette tendance au réchauffement semble avoir un lien de compensation avec un refroidissement dans l'hémisphère Sud.

Zusammenfassung. Die Verteilung der Temperatur in $10 \mathrm{~m}$ Tiefe auf dem Ross Ice Shelf. Dic Temperatur in Io $\mathrm{m}$ Tiefe ist auf dem Ross-Schelfeis zwischen 1958 und 1974 um I deg angestiegen. Auch die Oberflächentemperaturen an der "Byrd"-Station und bei McMurdo sind in dieser Periode gestiegen und die beobachteten Änderungen stimmen mit dem Anstieg in $10 \mathrm{~m}$ Tiefe überein. Diese Erwärmungstendenz scheint mit der Abkühlung auf der nördlichen Hemisphäre in einer gegensätzlichen Beziehung zu stehen.
\end{abstract}

TEN-Meter temperatures were measured over large areas of the Ross Ice Shelf during the International Geophysical Year of $1957^{-58}$ (Crary and others, I962) and in $1973-75$ as part of the Ross Ice Shelf Project (RISP). Comparison of the results reveals a consistent temperature increase over a large area of the eastern Ross Ice Shelf. In section I I describe the measurements and present the results, and in section 2 I discuss possible surface-temperature changes that could have caused the observed increase.

\section{Observations and Results}

During the austral summers $1973-74$ and I $974-75$ geophysical and glaciological measurements were made at a network of stations $50 \mathrm{~km}$ apart over the eastern half of the Ross Ice Shelf (reported in the July 1974 issue of Antarctic fournal of the United States). This program forms part of the RISP and similar measurements are planned for the remainder of the ice shelf.

At a selection of the stations, firn cores were collected by J. Nielsen of the University of Copenhagen, and ro $\mathrm{m}$ temperatures were measured using a glass-bead thermistor with a d.c. Wheatstone bridge. Positions of these stations are shown in Figure I. Convective air flow near the bottom of each hole was minimized by means of a polystyrene disk mounted above the thermistor so that it loosely plugged the hole. The thermistor usually remained down hole for at least one hour and often for several hours. After an initial settling period of $\mathrm{I} o$ to $15 \mathrm{~min}$, frequent resistance measurements were made and the corresponding temperatures were found to follow Newton's law of cooling closely. A semilogarithmic plot of the cooling curve was made for each set of measurements to give the equilibrium io m temperature. Measurements with different thermistors down the same hole, and with the same thermistor down adjacent holes, showed agreement to less than o. I deg.

At $10 \mathrm{~m}$ depth in the firn of Little America and Maudheim the annual temperature cycle has an amplitude of $0.4 \mathrm{deg}$ with a phase lag of about seven months (Crary and others, I962, p. 122). Assuming these values to be typical of the entire Ross Ice Shelf, the measured io $\mathrm{m}$ temperatures were corrected to corresponding annual averages. The resultant values are assumed to be accurate to $\pm 0.2 \mathrm{deg}$. 
Figure I shows individual plots of $10 \mathrm{~m}$ isotherms for both the I.G.Y. and the RISP measurements, with assigned epochs of $195^{8}$ and 1974 respectively. The 1974 isotherms form a pattern that is broadly similar to that deduced by Crary and others (1962) from the $195^{8}$ measurements. However, over most of the region, the temperatures have increased during the I6 year interval by approximately I deg.

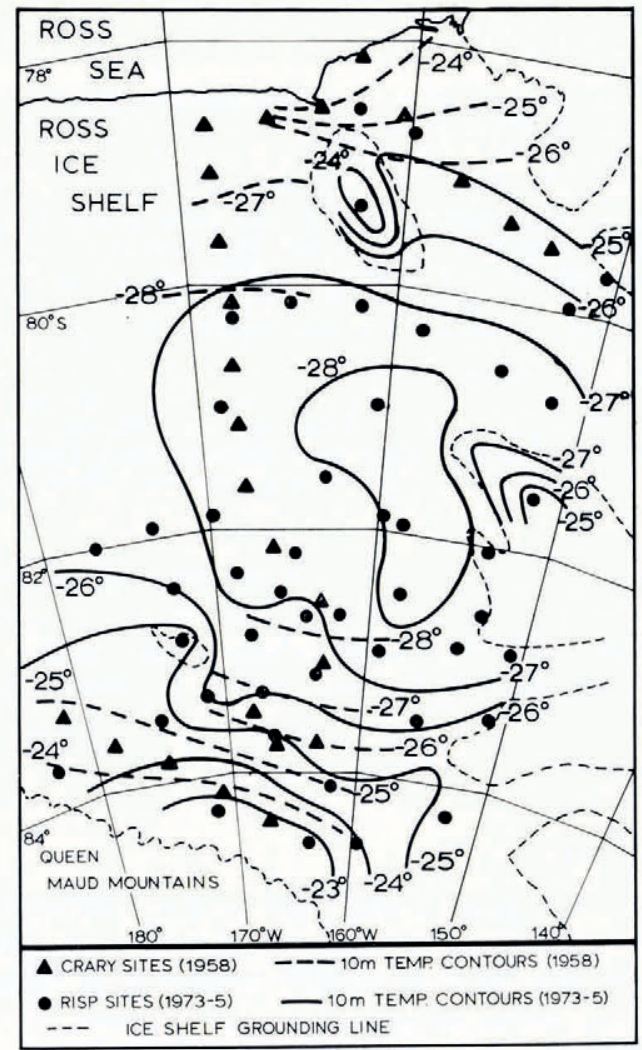

Fig. 1 . The eastern half of the Ross Ice Shelf showing $10 \mathrm{~m}$ isotherms for 1958 and 1974 and the positions where $10 \mathrm{~m}$ temperatures were measured.

\section{INTERPRETATION}

Ten-meter temperatures are representative, approximately, of the surface air temperature averaged over several years. Consequently, we may interpret the observed I deg increase as a change in average air temperatures. Figure 2 shows the variations in the annual mean temperature at the "Byrd" and McMurdo stations for the period I957-73. It was compiled from data in Budd (1975), where the temperature deviations at "Byrd" and McMurdo are plotted independently, and clearly follow very similar trends. Thus we might expect that temperatures over the Ross Ice Shelf, lying midway between "Byrd" and McMurdo, will follow the same trends, which may be approximated as a roughly cyclic variation superimposed on a warming of about 0.2 deg per year. This pattern shows good agreement with that deduced by Orheim (1972) for temperatures at Deception Island off the west coast of the Antarctic Peninsula. 


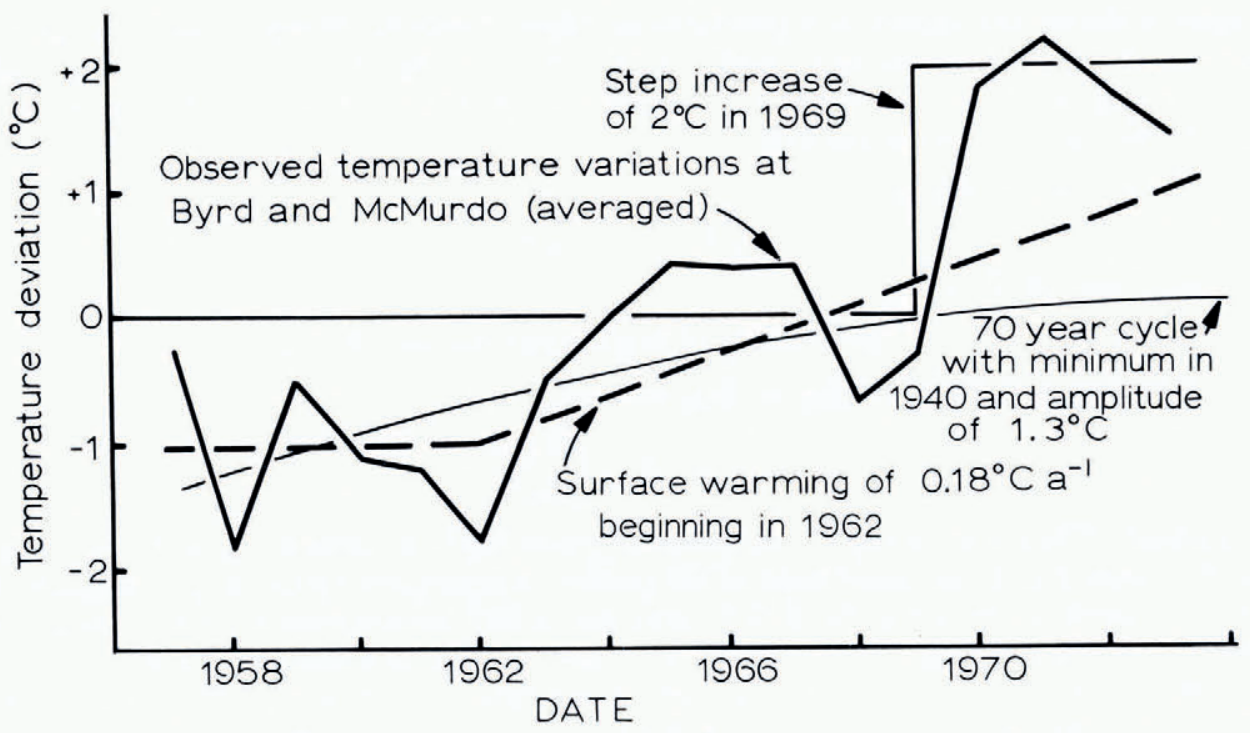

Fig. 2. Surface temperatures at "Byrd" and McMurdo stations expressed as deviations from the 1957-73 averages. The lines showing warming since 1962 , part of a 70 year cycle, and a step increase in 1969 , illustrate possible causes for the observed $I$ deg increase in $10 \mathrm{~m}$ temperatures.

In order to estimate the magnitude of the changes in annual mean surface temperature $\theta_{\mathrm{s}}$ necessary to produce the observed I deg increase in the $10 \mathrm{~m}$ temperatures I shall separately consider:

(i) a steady increase in $\theta_{\mathrm{s}}$ since some time $t_{0}$,

(ii) a cyclic variation of $\theta_{\mathrm{s}}$,

(iii) a step change in $\theta_{\mathrm{s}}$.

The calculations neglect the effects of snow accumulation. This approximation leads to an over-estimation of surface temperature changes necessary to produce the observed I deg increase. However, since the accumulation rates over most of the region are less than $10 \mathrm{~cm}$ of water per year (Clausen and Dansgaard, in press), the errors introduced by the approximation are less than those involved in the temperature measurement. To take account of the depth gradient of thermal diffusivity, the top $10 \mathrm{~m}$ of firn are considered as a pile of $\mathrm{I} \mathrm{m}$ thick layers each with a different density. The response to the annual surface temperature cycle is solved for each layer and excellent agreement is obtained with the observed phase lag and amplitude decay in the upper ro $m$ of firn at Little America if we adopt a relationship between thermal conductivity and firn density that is almost identical to that proposed by Yen (1965).

(i) for

$$
\theta_{\mathrm{s}}(t)=\theta_{0}+\alpha\left(t-t_{0}\right)
$$

where $\alpha$ is a constant and $t$ is time, the relevant equation for the temperature at depth $z$ in the firn is

$$
\theta_{z}(t)=\theta_{0}+4 \alpha\left(t-t_{0}\right) i^{2} \operatorname{erfc}\left(\frac{z}{2\left[\kappa\left(t-t_{0}\right)\right]^{\frac{1}{2}}}\right)
$$

(Carslaw and Jaeger, I959, p. 63) where $\kappa$ is the thermal diffusivity and where

$$
4 i^{2} \operatorname{erfc} x=\left[\left(\mathrm{I}+2 x^{2}\right) \operatorname{erfc} x-\frac{2}{\sqrt{ } \pi} x \exp \left(-x^{2}\right)\right]
$$


Figure 2 shows the surface temperatures at "Byrd" and McMurdo starting to increase in 1962 so $\left(t-t_{0}\right) \approx \mathrm{I} 2$ years and, with $\left(\theta_{\mathrm{IO}}(t)-\theta_{0}\right) \approx \mathrm{I} \mathrm{deg}$, Equation (I) was solved to

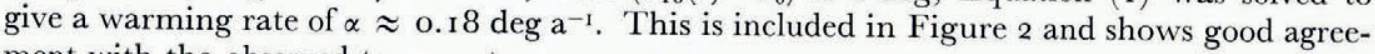
ment with the observed temperatures.

(ii) For cyclic variations in $\theta_{\mathrm{s}}$

with period $T=2 \pi / \omega$,

$$
\theta_{\mathrm{s}}(t)=\theta_{0}+A \cos (\omega t-\epsilon)
$$

$$
\theta_{z}(t)=\theta_{0}+A \exp (-\beta z) \cos (\omega t-\beta z-\epsilon)
$$

(Carslaw and Jaeger, I959, p. 64), where

$$
\beta=\left(\frac{\omega}{2 \kappa}\right)^{\frac{1}{2}} .
$$

The amplitude diminishes as $\exp (-\beta z)$ and the phase lag is $\beta z$ radians. In order to estimate minimum values for $A$, the amplitude of the surface temperature variations, we assume that the 16 year interval between the I.G.Y. and the RISP measurements represents an odd number of half wave lengths, with ro $\mathrm{m}$ temperatures in $195^{8}$ at a minimum and in 1974 at a maximum. Thus $(2 n+\mathrm{I}) T / 2=\mathrm{I} 6$ years and Equation (2) has been solved with $n$ taking integral values between $o$ and 4 . The corresponding values of $A$ are plotted against $T$ in Figure 3. For periods greater than 32 years the $195^{8}$ ten-meter temperature is assumed to represent a minimum and the graph becomes continuous.

The surface temperature variations shown in Figure 2 have a period of between 6 and i I years with amplitudes that are somewhat smaller than calculated from Equation (2):2.3 deg for $T \approx 6$ years and $1.6 \mathrm{deg}$ for $T \approx$ I I years. Furthermore the $195^{8}$ observed minimum in surface temperature is two years out of phase with that required for a $195^{8}$ minimum io $\mathrm{m}$ temperature.

A 32 year cycle requires only I deg amplitude at the surface, and the observations displayed in Figure 2 could represent part of such a cycle. However, observations from Deception

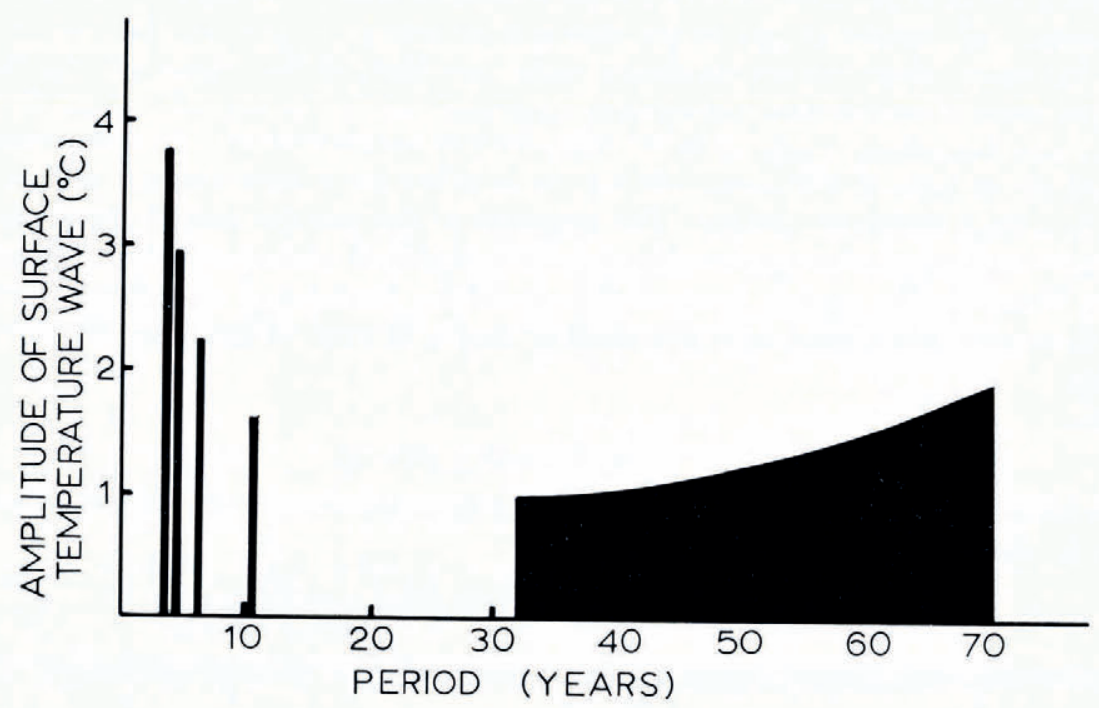

Fig. 3. The amplitude of cyclic surface temperature variations that could result in the observed $10 \mathrm{~m}$ warming plotted against
the period. 
Island (Orheim, 1972) and from the northern hemisphere (Dansgaard and others, 1975) do not show a near 30 year dominant period. Instead they both display temperature cycles having an approximately 70 year period with a northern hemisphere maximum and southern hemisphere minimum in about 1940. Assuming the Deception Island records to be typical of Antarctic conditions, implying a $10 \mathrm{~m}$ temperature minimum in 1945, the amplitude of the surface temperature cycle appropriate to the Ross Ice Shelf observations is $A=\mathrm{r} .3 \mathrm{deg}$.

This is plotted in Figure 2 and can be seen to be easily within the observed trend.

(iii) In I $969-70$ the temperatures at McMurdo and "Byrd" sharply increased by about 2 deg. The response of firn temperatures to a step change in surface temperature from $\theta_{0}$ to $\theta_{1}$ is expressed by

$$
\theta_{z}(t)=\theta_{0}+\left(\theta_{1}-\theta_{0}\right) \operatorname{erfc}\left(\frac{z}{2\left[\kappa\left(t-t_{0}\right)\right]^{\frac{1}{2}}}\right)
$$

(Carslaw and Jaeger, I959, p. 63), if, for a long time prior to $t_{0}$, the surface temperature was $\theta_{0}$. Clearly this is not the case at "Byrd" and McMurdo where there is a rising trend in temperature, and the effect of the assumption is to overestimate the magnitude of the step increase.

Equation (3) can be written

$$
\frac{\Delta \theta_{z}}{\Delta \theta_{\mathrm{s}}}=\operatorname{erfc}\left\{\frac{z}{2(\kappa \Delta t)^{\frac{1}{2}}}\right\}
$$

where $\Delta \theta_{z}=\theta_{z}(t)-\theta_{0}, \Delta \theta_{\mathrm{s}}=\theta_{1}-\theta_{0}, \Delta t=t-t_{0}$.

Equation (4) was solved to give $\Delta \theta_{\mathrm{I} 0} / \Delta \theta_{\mathrm{s}}$ for $\Delta t=0 \rightarrow 5^{\circ}$ years as shown in Figure 4 . Figure 4 is used to calculate the magnitude of the step increase $\Delta \theta_{\mathrm{s}}$ in surface temperature taking place during the period $195^{\circ} \leqslant t_{0} \leqslant 1972$, and the results are plotted in Figure 5 . There is a rapid increase in $\Delta \theta_{\mathrm{S}}$ for $t_{0}<195^{8}$ and for $t_{0}>1970$. The observed step-like increase in $\theta_{\mathrm{S}}$ shown in Figure 2 took place in 1969 when, from Figure $5, \Delta \theta_{\mathrm{S}} \approx 2$ deg, and this shows good agreement with the magnitude of the observed increase.

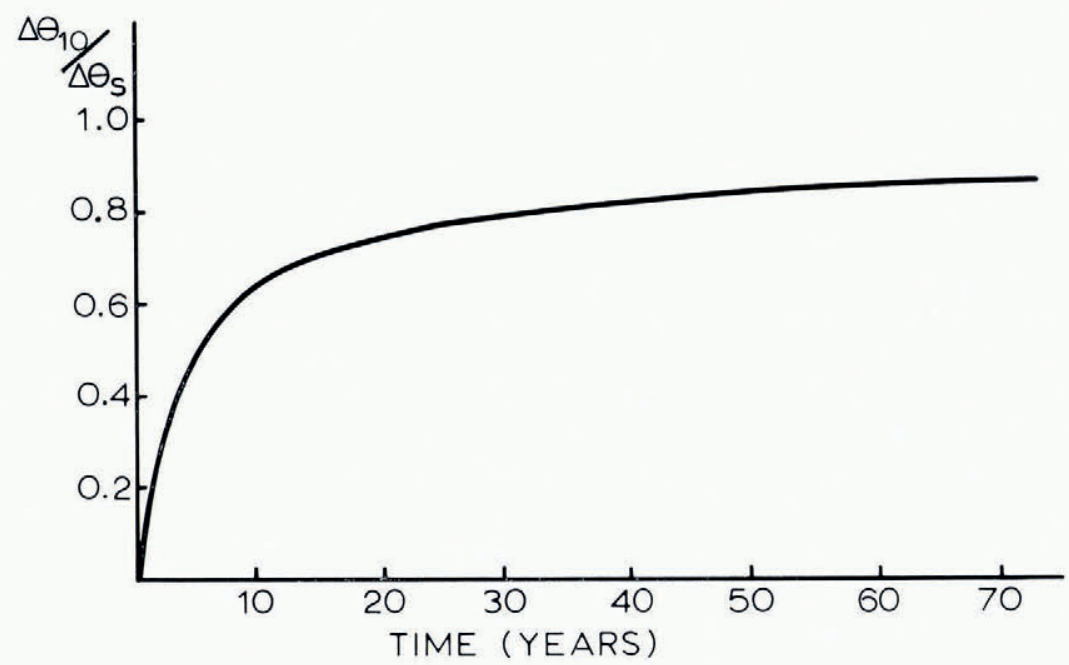

Fig. 4. The temperature response at $10 \mathrm{~m}$ depth $\left(\Delta \theta_{\mathrm{10}}\right)$ to a step increase $\left(\Delta \theta_{\mathrm{s}}\right)$ in surface temperature plotted against time. 


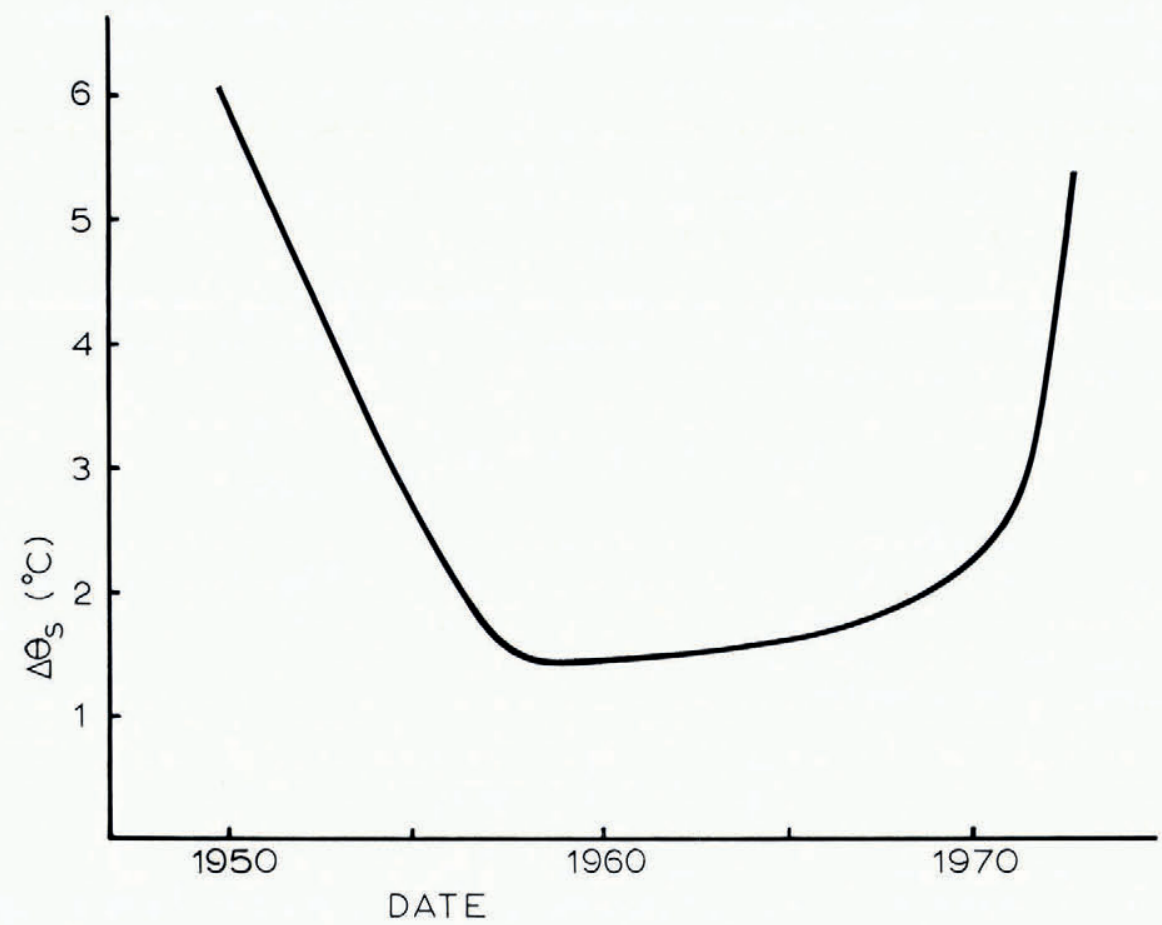

Fig. 5. The step increase $\left(\Delta \theta_{\mathbf{S}}\right)$ in surface temperature necessary to produce a Io $m$ warming of $I$ deg between $195^{8}$ and 1974 plotted against date of increase.

\section{Conclusions}

The I deg rise in Ross Ice Shelf ro m temperatures between $195^{8}$ and I974 can be explained by any of these mechanisms:

(i) A steady surface warming since 1962 of $0.18 \mathrm{deg} \mathrm{a}^{-1}$.

(ii) Cyclic variations in surface temperature with periods of $6, \mathrm{I}, 32$ and 70 years and having their respective maxima in 1972, 1972, 1970 and 1975. Records from elsewhere favor the i 1 and 70 year cycles.

(iii) A 1969 step increase in surface temperature of $2 \mathrm{deg}$.

Surface temperature measurements at "Byrd" and McMurdo stations display a general warming since 1958 with a step-like increase in $1969-70$ and the magnitude of these changes is sufficient to explain the observed increase in Ross Ice Shelf ro $\mathrm{m}$ temperatures. However, the observation period at "Byrd" and McMurdo is too short to indicate whether the observed warming is part of a long-period cyclic change. Accurate temperature measurements in the upper $100 \mathrm{~m}$ of ice shelf may help to solve this problem, and temperatures in a $100 \mathrm{~m}$ hole at lat. $82^{\circ} 22^{\prime}$ S., long. $168^{\circ} 40^{\prime} \mathrm{W}$. were measured by John Rand of the Cold Regions Research and Engineering Laboratory during December i974. Unfortunately, at the time of writing, the results are not available. Oxygen isotope analysis of ice from the $100 \mathrm{~m}$ bore hole should reveal major temperature changes that have occurred during the last 800 years.

The evidence for warming in the Ross Ice Shelf area provided by the $10 \mathrm{~m}$ temperature increase and by the observations at "Byrd" and McMurdo is consistent with evidence from Deception Island off the west coast of the Antarctic Peninsula. The reconstructed surface temperature history at Deception Island (Orheim, I972) has a 70 year cycle that is $180^{\circ}$ out of 
phase with a similar temperature cycle deduced from oxygen-isotope analysis of Greenland ice cores (Dansgaard and others, 1975). This antiphase relationship between northern and southern hemisphere temperature records provides support for Fletcher's (I972) suggestion that increased sea ice around Antarctica should lead to increased vigour of atmospheric circulation, a northward shifting of the meteorological equator, and warming in the northern hemisphere.

\section{Acknowledgements}

I am particularly grateful to J. Nielsen, who measured most of the RISP ro m temperatures, and to the Cold Regions Research and Engineering Laboratory for the loan of thermistors and a Wheatstone bridge. The work was supported by National Science Foundation Grant $\mathrm{OPP}_{74-00475}$ Aor.

\section{REFERENCES}

Budd, W. F. 1975. Antarctic sea-ice variations from satellite sensing in relation to climate. Fournal of Glaciology, Vol. 15, No. 73, p. 417-27.

Carslaw, H. S., and Jaeger, J. C. 1959. Conduction of heat in solids. Second edition. Oxford, Clarendon Press.

Clausen, H. B., and Dansgaard, W. In press. Less surface accumulation on the Ross Ice Shelf than hitherto assumed. [Paper presented at the International Union of Geodesy and Geophysics sixteenth General Assembly, International Symposium on Isotopes and Impurities in Snow and Ice, Grenoble, 1975.]

Crary, A. P., and others. 1962. Glaciological studies of the Ross Ice Shelf, Antarctica, 1957-1 960, by A. P. Crary, E. S. Robinson, H. F. Bennett and W. W. Boyd, Jr. IGY Glaciological Report Series (New York), No. 6.

Dansgaard, W., and others. 1975. Climatic changes, Norsemen and modern man, [by] W. Dansgaard, S. J. Johnsen, N. Reeh, N. Gunderstrup, H. B. Clausen and C. U. Hammer. Nature, Vol. 255, No. 5503, p. $24-28$.

Fletcher, J. O. 1972 . Ice on the ocean and world climate. (In Beneficial modifications of the marine environment. A symposium sponsored by the National Research Council, National Academy of Sciences, National Academy of Engineering and the U.S. Dept. of the Interior, March II, I968, Washington, D.C. Washington, D.C., National Academy of Sciences, p. 4-49.)

Orheim, O. 1972. A 200-year record of glacier mass balance at Deception Island, southwest Atlantic Ocean, and its bearing on models of global climatic change. Ohio State University. Institute of Polar Studies. Report No. 42.

Yen, Y. C. 1965. Effective thermal conductivity and water vapor diffusivity of naturally compacted snow. Journal of Geophysical Research, Vol. 70, No. 8, p. 1821-25.

\section{DISCUSSION}

W. S. B. Paterson: Does the 70-year cycle show in the "Byrd" or Little America oxygen isotope profiles?

R. H. Thomas: The near-surface "Byrd" cores have only recently been recovered and have not yet been analysed, and the results from the Little America cores have not been published.

W. F. BudD: Do you think you would obtain the observed ro $\mathrm{m}$ temperature difference if you used as input to the heat conduction equation the observed annual mean temperature record that you presented?

Thомаs: I think we would get slightly more than the observed difference.

PAterson: Is there any melting in summer on the Ross Ice Shelf?

Tномаs: There is virtually no melting and pits reveal only very thin ice layers. 